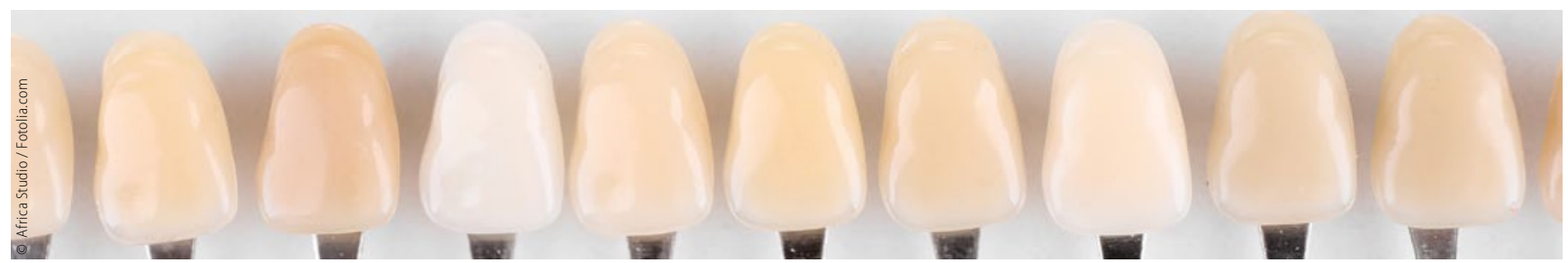

Qualitätsmerkmal: Reproduzierbarkeit

\title{
Anwendungen und Prinzipien der automatischen Farbbestimmung
}

Die üblichste Farbbestimmung führt bis heute der behandelnde Zahnarzt oder Zahntechniker mit Hilfe von Farbpaletten durch. Dabei ist auch die Farbe des umgebenden Lichts von großer Bedeutung: Neonlicht, Tageslicht oder Halogenlicht. Während der vergangenen Jahre ist das Interesse an der automatischen Farberkennung stark gestiegen.

Ein wichtiges Qualitätsmerkmal bei der automatisierten Farbbestimmung ist die Reproduzierbarkeit, die mit Hilfe standardisierten Lichts ermöglicht wird.

Dabei müssen die topographischen Regionen nahe der Gingiva von den mittleren Regionen und der Inzisalkante unterschieden werden. Diese Reproduzierbarkeit kann die Kommunikation von Zahnarzt und Zahntechniker bei der Farbauswahl erleichtern oder aber auch beim Bleachen den Behandlungserfolg bestätigen. Im Zeitverlauf kann die Verfärbung der Zähne objektivierbar überprüft werden.

Zur Beschreibung der Zahnfarbe ist nicht nur die Farbe selbst, sondern sind auch die Transluzens und Farbsättigung entscheidend. Wegen der Zusammensetzung aus Pulpa, Dentin und Schmelz schließt eine genaue Farbbestimmung auch die Betrachtung des Zahnstumpfes ein. Zur Farbbestimmung kommen die Prinzipien Spektrophotometer, Kalorimeter und Imaging (Bildgebungs-)Systeme zur Anwendung.

\section{Digitale Fotografie integrieren}

Spektrophotometer messen die von einer Oberfläche reflektierte Lichtmenge an verschiedenen Punkten in einem Abstand von 1 bis 25 Nanometer (nm). Die Messergebnisse werden dann in die Bezeichnung der gewohnten Farbskala übersetzt. Manche Systeme kombinieren die Spektrophotometry mit der digitalen Photographie. Die Farbbestimmung erfolgt dabei mit einem LED-Licht im Mund, damit möglichst wenig externes Licht stört. Kalorimeter hingegen bilden den Zahn mit Hilfe verschiedener Farbfilter ab. Dabei werden die Regionen des Zahnes im gingivalen, mittleren und inzisalen Anteil getrennt gemessen.

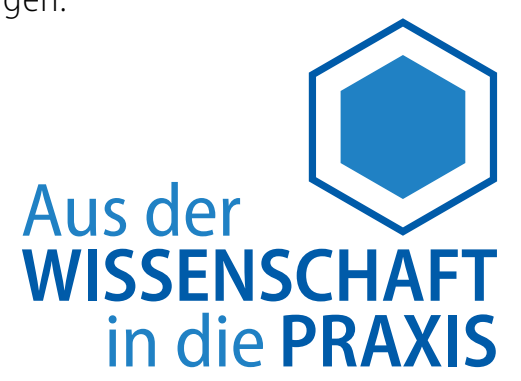

Die einfachste Methode der Farbbestimmung macht sich die digitale Fotografie zu Nutze, wobei bei dem RGB-Farbmodell rotes, grünes und blaues Licht addiert wird. Die Farbwiedergabe des digitalen Bildes kann dann per Softwareunterstützung mit einer Farbdatenbank abgeglichen werden.

Die komplette Zahnoberflächenmessung bildet die Zahnfarben zweidimensional ab. Dabei werden jedoch nicht die Form, die Oberflächenbeschaffenheit, die Dicke der Restauration oder das Kernmaterial des Zahnes berücksichtigt.

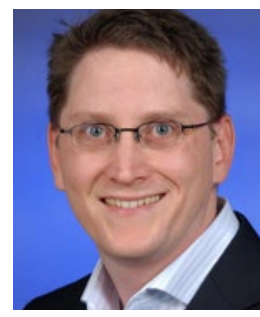

Dr. Dr. Felix P. Koch

Autor des Wissenschaftlichen Info-Dienstes, stellvertretender Klinikdirektor und Leitender Oberarzt für Mund-, Kiefer- und Gesichtschirurgie der Uniklinik Frankfurt/Main. 